\section{Tratamiento de una periodontitis apical crónica reagudizada con pasta}

\section{Mix-MP}

\author{
Sharpened chronic apical periodontitis treatment with pasta 3 Mix-MP
}

\section{Resumen}

El propósito de este caso clínico es mostrar el uso como medicación intraconducto de la pasta de Hoshino (3Mix-MP). Paciente de sexo femenino acude a la clínica de posgrado con el diagnóstico clínico de necrosis pulpar con periodontitis apical crónica de la pieza 42. Se le realizó un tratamiento endodóntico en el año 2013; en el año 2014 regresa con lesión apical más severa y con un diagnóstico de periodontitis apical con fístula extraoral. La paciente no desea perder la pieza dentaria, por lo que se evalúa la posibilidad de tratamiento de segunda intención no quirúrgica utilizando la pasta de 3 MIX-MP como medicación intraconducto. Se realizaron controles por 3 meses con medicación intraconducto, clínicamente se evaluó la desaparición de la fístula observándose radiográficamente la disminución de la lesión periapical mejorando el pronóstico, por lo que se procede a obturar la pieza dentaria y se evalúo radiográficamente en 12 meses observándose reparación ósea. Procediéndose a restaurar protésicamente la pieza.

Palabras clave: Periodontitis apical crónica, 3 Mix-MP, medicación intraconducto.

\section{Abstract}

The purpose of this case is to show the use of intracanal medication Oshino paste (3Mix-MP). A patient who had a pulp necrosis with chronic apical periodontitis in the piece 42 , underwent endodontic treatment in 2013, but in 2014 returns with a more severe apical lesion and the diagnosis of apical periodontitis, extra oral fistula; the patient did not want to lose the tooth so that the possibility of nonsurgical treatment of second intention using paste 3 MIX-MP as intracanal medication was evaluated. Controls for 3 months with intracanal medication were performed, the clinical disappearance of fistula was observed and periapical lesion decrease, improving the prognosis. So we proceed to seal the tooth and evaluated for 12 months, coming to observe bone repair, then the prosthetic restoration of the piece was done.

Keywords: Chronic apical periodontitis; 3 Mix-MP; Intracanal medication.
Caso Clínico
Maycol Hinostroza del Pino',2, Doris Salcedo-Moncada',2, Sonia Zambrano de la Peña ${ }^{3}$, Martha Pineda-Mejía ${ }^{1,2}$

1. Unidad de Posgrado de la Facultad de Odontología de la Universidad Nacional Mayor de San Marcos, Perú.

2. Departamento Académico de Estomatología Rehabilitadora de la Facultad de Odontología de la Universidad Nacional Mayor de San Marcos, Perú.

3. Departamento Académico Médico Quirúrgico de la Facultad de Odontología de la Universidad Nacional Mayor de San Marcos, Perú.

Correspondencia:

C.D Maycol Hinostroza del Pino

Facultad de Odontología de la Universidad Nacional Mayor de San Marcos, Jr. Amezaga 375, Lima 1, Perú.

Correo electrónico: maycolhdp@hotmail.com

Coautores

Salcedo: endodoncista@hotmail.com

Zambrano: facedent@hotmail.com

Pineda: mpinedam@unmsm.edu.pe

Recibido: 11-09-15

Aceptado: 11-12-15

\section{Introducción}

La periodontitis apical crónica es un proceso inflamatorio y/o infeccioso de poca intensidad y de larga duración, localizado a nivel de los tejidos periapicales del diente y caracterizado por la presencia de acumulación purulenta ${ }^{1}$. Consiste en la formación de un exudado periapical purulento con un drenaje espontáneo hacia el exterior a través de un trayecto fistuloso ${ }^{2}$. Su comportamiento clínico es asintomático, radiográficamente se observa una imagen radiolúcida, ya sean extensas o pequeñas y circunscriptas. Se debe tratar el conducto radicular infectado por medio de terapia endodóntica ${ }^{1}$.

Cuando la pulpa se expone a la microbiota bucal a través de una cavidad, el tejido pulpar se ve expuesto a concentraciones mayores de productos microbianos. En esta situación, el tejido pulpar no consigue impedir la infiltración y la diseminación de los microorganismos o de sus productos y comienzan a desintegrarse porciones de la pulpa. La necrosis es inevitable y se crean condiciones favorables para una infección pulpar masiva ${ }^{3}$.

La lesión periapical es causada por bacterias en el espacio del conducto radicular. El objetivo más importante de la terapia de conducto radicular es reducir al mínimo el número de microorganismos en sistemas de conductos radiculares ${ }^{4}$.

La eliminación de la contaminación microbiana del sistema de conductos radiculares es un prerrequisito para el éxito de un tratamiento radicular. $\mathrm{La}$ preparación biomecánica y la conformación de los canales de la raíz reducen en gran medida el número de bacterias, pero se ha demostrado que es imposible obtener una desinfección completa en todos los casos. Después de la ins- trumentación y la irrigación, el uso de medicamentos entre sesiones ha sido ampliamente defendido porque contribuye a la desinfección del sistema de conductos radiculares en todo su período de aplicación, penetrando además en los túbulos dentinarios para eliminar las bacterias que afectan los tejidos perirradiculares ${ }^{5}$.

En las periodontitis se producen reabsorciones del ápice, formándose cráteres en los que anidan bacterias y pueden permanecer inaccesible al tratamiento. La falta de una medicación intraconducto disminuye el porcentaje de éxito en los dientes con conductos ${ }^{5}$ infectados ${ }^{6}$.

Cabe resaltar que la elección de una medicación intraconducto entre sesiones requiere de las mismas consideraciones que la aplicación de cualquier fármaco en otra región del organismo humano, por lo tanto, es necesario considerar: 
1. Dosis: se debe precisar la cantidad y concentración del fármaco, para ejercer el efecto deseado sin lesionar los tejidos circundantes. En conductos estrechos, las condiciones son diferentes de las halladas en conductos amplios.

2. Localización: es indispensable tener en cuenta el mecanismo de acción de las sustancias para determinar la forma apropiada para su colocación. Por ejemplo, en los casos de mortificación pulpar con rarefacción periapical, al utilizar hidróxido de calcio que actúa por contacto, debe llenarse todo el conducto radicular.

3. Tiempo de aplicación: es preciso conocer el tiempo que la sustancia permanece activa. Cada una tiene un tiempo de vida útil, después del cual su efecto se reduce o desaparece. Algunos medicamentos pierden sus propiedades en presencia de material orgánico como sangre, exudado y pus.

La selección del fármaco debe tomar en consideración que los antisépticos capaces de controlar la infección pueden ocasionar también irritación o destrucción de los tejidos vivos periapicales ${ }^{6}$.

\section{Pasta 3Mix-MP. Hoshino}

La pasta triple antibiótica 3Mix ha sido desarrollada durante los últimos años como una nueva manera de tratar las piezas deciduas necróticas indicadas para tratamientos de pulpectomías, facilitando su procedimiento y mejorando los resultados clínicos. Los estudios realizados ${ }^{8,9}$ han demostrado que 3 Mix es capaz de eliminar las bacterias de tejidos dentales infectados de dientes deciduos y permanentes, constituyéndose como una excelente alternativa para piezas deciduas indicadas para tratamientos de pulpectomía. Otros estudios han demostrado su eficacia en tratamientos endodónticos en piezas permanentes, por ejemplo, como medicación intraconducto en casos de retratamientos, infecciones recurrentes por enterococcus faecalis o en casos de lesiones periapicales crónicas producto de perforaciones radiculares ${ }^{10,11}$. Sin embargo, son estudios preliminares aunque no por ello menos importantes. La pasta $3 \mathrm{Mix}-\mathrm{Mp}$ consta de dos partes: polvo y líquido. El polvo está formado por una combinación de tres antibióticos, los cuales son: metronidazol, ciprofloxacina y minociclina en una proporción de 1:1:1; y la parte líquida es una combinación de macrogol y propylen glicol, también en proporción 1:1, estos últimos actúan como vehículos de los antibióticos. La pasta 3 Mix Mp tiene como principal indicación ser preparada el mismo día del tratamiento. Para su preparación se adquirirán los medicamentos en su forma comercial, debiendo ser conservados en sus respectivos empaques. La preparación de la pasta 3 Mix Mp debe ser hecha preferentemente por el operador para estar seguro de la consistencia ideal y de las proporciones correctas. La pasta debe ser usada durante el día de su preparacion, la cantidad sobrante deberá ser eliminada al final de las horas de trabajo $^{10}$.

Sato y col. ${ }^{9}$ evaluaron in vitro la eficacia antibacteriana de una mezcla de ciprofloxacina, metronidazol y minociclina (3Mix), con y sin la adición de rifampicina (100 g de cada uno/ml) (4Mix), contra las bacterias orales de los niños, observando que las combinaciones mencionadas eran eficaces contra las lesiones cariosas y endodónticas.

La combinación de irrigación y desinfección con la pasta triple antibiótica permite el cierre del ápice radicular en el procedimiento de endodoncia regenerativa y la curación de las lesiones periapicales en la terapia de endodoncia no quirúrgica. El uso de propilenglicol permite la entrada eficiente y profunda en los túbulos dentinarios y más allá del cemento, mejorando así la curación de grandes lesión periradiculares. 3Mix puede ser utilizado como material de relleno de conductos radiculares de dientes primarios ${ }^{12,13}$.

\section{Caso clínico}

Paciente de 54 años, de género femenino, refiere que fue atendida en el año 2013 con un diagnóstico de necrosis pulpar en pieza 42 y le realizaron un tratamiento de conducto y en el ańo 2014 se presenta a consulta en la clínica de Posgrado de Endodoncia con manifestación de dolor. Refiere que se le hinchaba la cara cada cierto tiempo y se automedicaba, actualmente sufre de artritis y está en tratamiento con corticoides. Al examen clínico presenta fístula extraoral por debajo de zona mentoniana (Fig. 1). Radiográficamente se observó la pieza 42 con tratamiento previo y con periodontitis apical crónica con una pérdida ósea severa a nivel apical (Fig 2,3).

Después del examen clínico se indicó radiografía de diagnóstico y al observar una imagen radiolúcida muy amplia se solicitó una radiografía Panorámica. El diagnóstico fue pieza 42 con trata- miento previo con periodontitis apical crónica y se programó realizar el retratamiento utilizando la técnica híbrida. Se procedió a desobturar el conducto radicular, para así poder realizar el drenaje por el mismo conducto (Fig 4), luego de lo cual se le da medicación antibiótica (clindamicina $300 \mathrm{mg}$ ) por 7 días.

En la segunda cita programada después de 7 días, se procedió a aplicar la técnica híbrida. Se inició con la técnica corono apical sin presión apical, iniciando el tercio cervical con limas flexofile $\# 60,55,50,45,, 40$ para luego realizar la conductometría, e irrigar abundantemente con hipoclorito de sodio de $2.5 \%$. Luego se usa la técnica apico coronal en el tercio apical, se seca con conos de papel \# 35 y se coloca solamente una medicación intraconducto a base de la pasta de 3 Mix-Mp (Fig 5, 6, 7), citando a la paciente luego de 15 días .

En la tercera cita después de 15 días programados, se observa una evolución favorable en la paciente, asintomática, y la fístula está en remisión. Se procede a irrigar con hipoclorito de sodio al $2.5 \%$ y se vuelve a instrumentar manualmente el conducto con lima Flexofile \# 20,25,30,35, en tercio apical, previo secado con conos de papel \#35 se coloca solo la medicación intraconducto 3 Mix-Mp, con la finalidad de evaluar después de 30 días (Fig 8, 9).

Ya en la cuarta cita, después de 52 días de iniciado el tratamiento, se procede a realizarle un cultivo microbiológico del conducto, encontrándose resultados favorables con disminución de carga bacteriana evaluado por la disminución de la turbidez de la muestra (Fig 10). Se irriga nuevamente con hipoclorito de sodio al $2.5 \%$, se seca con conos de papel\# 35 y se le deja solo medicación intraconducto $3 \mathrm{Mix}-\mathrm{Mp}$, por un periodo de 2 meses más.

En la quinta cita, después de 112 días de tratamiento, la paciente regresa al servicio manifestando que no ha tenido ningún tipo de sintomatología, clínicamente no se observa ningún tipo de inflamación o edema en la zona. Se procede a la obturación de la pieza dentaria, colocación de corona provisional de resina y fotografía de control final sin fístula (Fig 11, 12, 13).

$\mathrm{Al}$ control de un año, la paciente refiere estar asintomática, ha sido derivada al servicio de Rehabilitación Oral para continuar su rehabilitación definitiva y se indica controles cada año. 


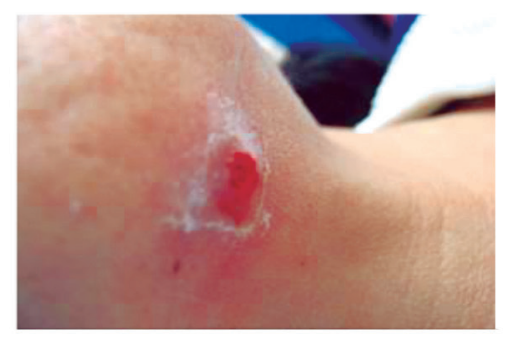

Fig. 1 Fístula extraoral pieza 42

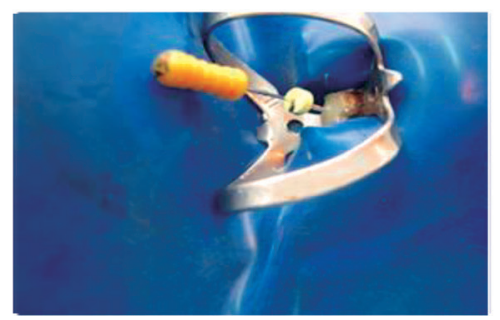

Fig. 4. Desobturación

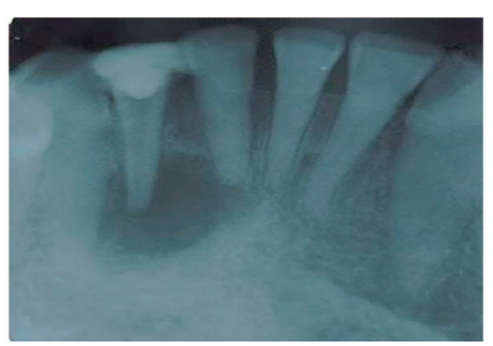

Fig. 7 Control con pasta 3mix-MP

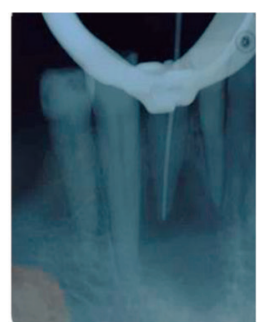

Fig. 10

Conductometría

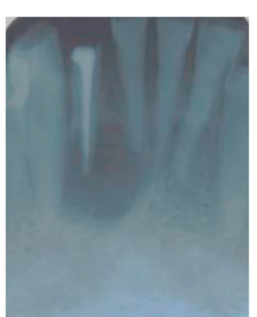

Fig. 11 Rx.Obturación

\section{Discusión}

Sato y Hoshino observaron el potencial de la mezcla de ciprofloxacino, metronidazol y minociclina para eliminar las bacterias en las capas más profundas del conducto radicular ${ }^{9,11}$. La combinación de antibióticos que conforman esta pasta tiene la capacidad de atravesar la dentina actuando así sobre la lesión. De los tres antibióticos inhibe la presencia de microorganismos en la lesión periapical, para este caso la medicación de selección debió tener un amplio espectro de acción y de actuar por un periodo prolongado, también debió modular la inflamación de los tejidos periapicales, responsables del proceso de

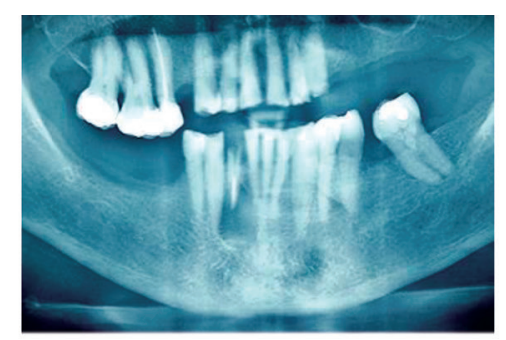

Fig. 2. Radiografía panorámica de diagnóstico

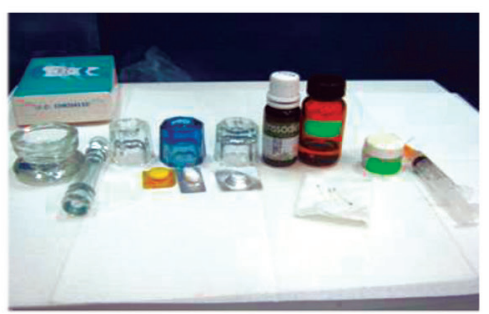

Fig. 5. Componentes de la pasta 3 mix-Mp

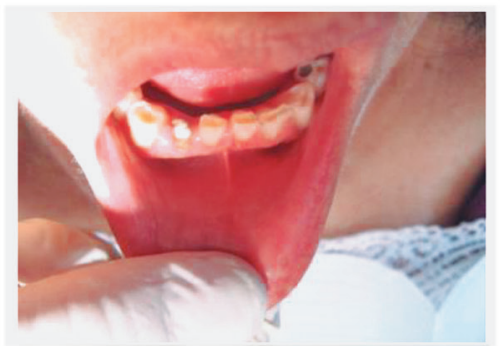

Fig. 8 Control clínico

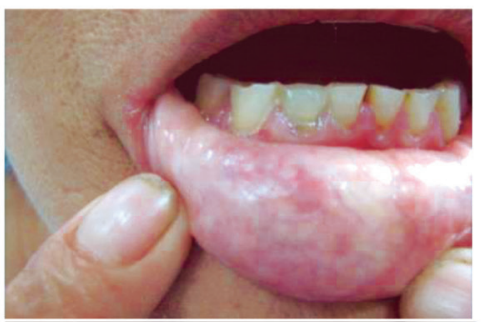

Fig 12.

Reconstrucción provisional de resina

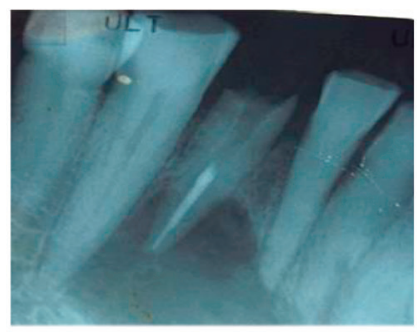

Fig. 3. Radiografía periapical pza 42

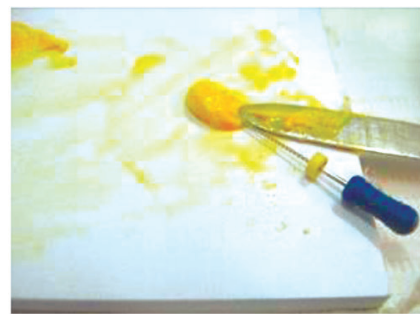

Fig. 6. Pasta 3 Mix-Mp

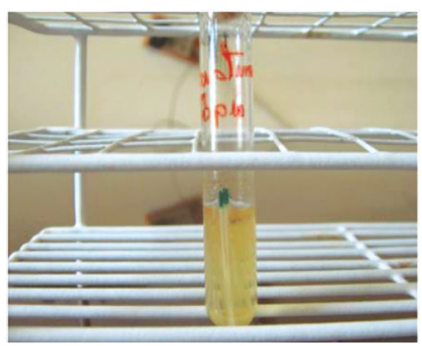

Fig. 9 Control microbiológico

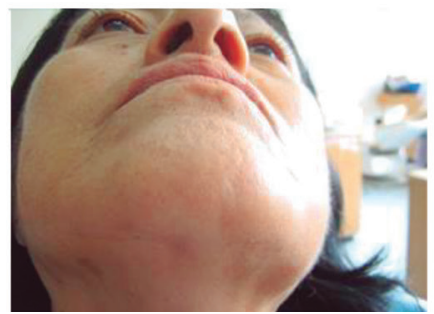

Fig. 13

Control final reparación, neutralizar los restos orgánicos que pudieran estar presentes, además de ayudar a secar los conductos persistentemente húmedos por el exudado por lo cual la elección de la pasta 3 Mix-Mp fue la más consistente para este caso clínico.

Takushige y col. demostraron en un estudio que la recuperación de bacterias disminuye con el tiempo después de la aplicación de la combinación de

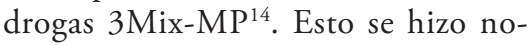
torio en el caso presentado, cuando se realizó el cultivo microbiológico y observamos disminución de turbidez a su vez por las mejorías tanto clínicas como radiográficas después de haber realizado el tratamiento.
Una revisión del año 2012 concluyó que la combinación de irrigación y desinfección con el protocolo de triple pasta antibiótica permite el cierre del ápice radicular en el procedimiento de endodoncia regenerativa y la curación de las lesiones periapicales en la terapia de endodoncia no quirúrgica. La adición de 3Mix con propilenglicol y politilenglicol permite la entrada eficiente y profunda en los túbulos dentinarios y más allá del cemento, mejorando así la curación de gran lesión perirradicular ${ }^{13}$; en nuestro estudio se aplicó dicho concepto y obtuvimos resultados muy satisfactorios con disminución de la lesión perirradicular y cicatrización total de la fístula extraoral, permitiendo la rehabilitación posterior de la paciente. 


\section{Conclusiones}

Al realizar el tratamiento con la pasta Hoshino (3Mix-MP) se observó mejorías tanto clínicas como radiográficas lo que indica su efectividad en el tratamiento no quirúrgico de una periodontitis apical crónica en una pieza dentaria con tratamiento previo y la recuperación clínica observada en la paciente se debe a que esta pasta $3 \mathrm{Mix}-\mathrm{Mp}$ tiene la capacidad de penetrar rápidamente en la dentina radicular y actuar contra las bacterias presentes debido a su eficacia antibacteriana in situ.

\section{Referencias bibliográficas}

1. Cohen S, Burns R. Endodoncia. Los caminos de la pulpa. $4^{a}$ ed. Buenos Aires. Argentina: Médica Panamericana; 1991.

2. Muñante C J. Identificación de microorganismos anaerobios estrictos y facultativos frecuentes en necrosis pulpares. Tesis para optar el título de Cirujano Dentista. Lima, Perú; 2005.

3. Navia M, Shin I. Identificación y cuantificación microbiológica de bacterias en conductos necróticos. Canal Abierto. Rev. Sociedad de Endodoncia de Chile. No 12. Octubre. 2005.

4. El Karim I, Kennedy J, Hussey D. The antimicrobial effects of root canal irrigation and medication. Oral Surg Oral Med Oral Pathol Oral Radiol Endod 2007;103:560-9. DOI: 10.1016/j. tripleo.2006.10.004

5. Siqueira JF Jr, de Uzeda M. Intracanal medicaments: Evaluation of the antibacterial effects of chlorhexidine, metronidazole, and calcium hydroxide associated with three vehicles. J Endod 1997 march; 23(3): 167-169. DOI: 10.1016/S0099-2399(97)80268-3

6. Canalda C, Brau E. Endodoncia: Técnicas clínicas y Bases científicas. Espańa: Masson; 2001.

7. Sánchez J. Influencia del hidróxido de calcio como medicación intra conducto en la microfiltración apical. ROM. 2011; 15(4)

8. Alireza Adl. The Ability of Triple Antibiotic Paste and Calcium Hydroxide in Disinfection of Dentinal Tubules. Iranian Endodontic Journal 2014; 9(2)123-126

9. Sato I, Ando-Kurihara N, Kota K, Iwaku M, Hoshino E. Sterilization of infected root-canal dentine by topical application of a mixture of ciprofloxacin, metronidazole and minocycline in situ. Int Endod J. 1996 Mar;29(2):118-24.
10. Takushige et. al. Clinical Evaluation of Endodontic Re-Treatment Using LSTR 3 Mix- MP. Niigata University. Japón, 2007. [Citado: 2015/10/10]. Disponible en: http://iadr.confex.com/ iadr/2007orleans/techprogram/ abstract_91540.htm

11. Hoshino E. Tamanna. Susceptibility of enterococcus faecalis to a combination of antibacterial drugs (3Mix) in vitro. J. Oral Biosci. 2005; 47(4):315-320

12. Windley W. et al. Desinfection of Immature teeth with a triple antibiotic paste. J Endod. 2005; 31(6): 439-443

13. Varalakshmi R Parasuraman, Banker Sharadchandra Muljibhai. "3Mix- MP in Endodontics - An overview". Journal of Dental and Medical Sciences (JDMS). 2012; 3(1):36-45.

14. Quispe A. Evaluación del efecto antibacteriano de la combinación de drogas 3 mix en bacterias anaerobias prevalentes en necrosis pulpar. [tesis para el título de Cirujano dentista]: Lima: Universidad Nacional Mayor de San Marcos; 2007. Disponible en: http://www. cybertesis. edu.pe/sisbib/2007/ quispe_sa/pdf/ quispe_sa.pdf 